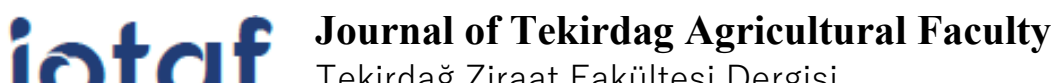 \\ Tekirdağ Ziraat Fakültesi Dergisi
}

\section{Soya Bitkisinin Verim Parametreleri ile Bazı Kimyasal Toprak Özellikleri Arasındaki Pedotransfer Modellerin Uygulanabilirliği}

Applicability of Pedotransfer Models between Yield Parameters and Some Chemical Soil Properties of SoybeanPlant

\section{Nalan KARS ${ }^{1}$, İmanverdi EKBERL $\dot{I}^{* *}$}

\section{$\ddot{\mathbf{O} z}$}

Bu çalışmanın amacı, Çarşamba Ovasında yetiştirilen soya bitkisinin verim parametreleriyle (bitki boyu, bin tane ağırlığı ve tane verimi) toprakların bazı kimyasal özellikleri arasındaki korelasyon ilişkilerine dayanarak, bu özellikler arasında pedotransfer modellerin oluşturulması ve elde edilen modellerin ova topraklarında bitki veriminin tahmininde uygulanabilirliğinin belirlenmesidir. Bu amaçla, ovanın çiftçiler tarafından soya tarımı yapılan arazilerinden rastgele örnekleme metodu ile alınan 40 toprak ve bitki örneklerinde analizler yapılmıştır. Soya bitkisinin bitki boyu, bin tane ağırlığı ve tane verimi değerleri sırasıyla; 88.33-127.27 cm, 164.10-242.91 g ve $280.32-593.16 \mathrm{~kg} \mathrm{da}^{-1}$ arasında değişmiştir. Soya bitki boyu değeriyle bin tane ağırlı̆̆ı arasında önemli pozitif $\left(0.476^{*}\right)$; bitki boyu ile topraklardaki bakır $(\mathrm{Cu})$ miktarı arasında ise çok önemli pozitif ilişkiler $\left(0.484^{* *}\right)$ belirlenmiştir. Soya tane verimi değeri ile topraklardaki potasyum $(\mathrm{K})$ ve fosfor $(\mathrm{P})$ miktarları arasında önemli pozitif ilişkiler $(0.384 *$ ve $0.382 *)$ saptanmıştır. Bitki boyu ile azot $(\mathrm{N}), \mathrm{P}, \mathrm{K}$, organik madde $(\mathrm{OM})$, katyon değişim kapasitesi (KDK), elektriksel iletkenlik $(\mathrm{EC}), \mathrm{Cu})$, kireç $\left(\mathrm{CaCO}_{3}\right)$ parametreleri arasındaki pedotransfer modeli istatistiksel olarak anlamlı $(\mathrm{p}=0.078)$, belirleme katsayısı $(\mathrm{R}=0.721)$ yüksek; bin tane ağırlığı ile $\mathrm{EC}, \mathrm{OM}$, $\mathrm{KDK}$, kalsiyum+magnezyum $(\mathrm{Ca}+\mathrm{Mg}), \mathrm{N}, \mathrm{P}, \mathrm{K}, \mathrm{CaCO}_{3}$, sodyum $(\mathrm{Na}), \mathrm{Cu}$, çinko $(\mathrm{Zn})$ parametreleri arasındaki model istatistiksel olarak anlamlı farklılık saptanmamış, belirleme katsayısı $(\mathrm{R}=0.664)$ yüksek; tane verimi ile $\mathrm{EC}$, $\mathrm{CaCO}_{3}, \mathrm{OM}, \mathrm{N}, \mathrm{P}, \mathrm{K}, \mathrm{Zn}, \mathrm{Mn}$ parametreleri arasındaki modelin performansı çok yüksek $(\mathrm{R}=0.921 ; \mathrm{p}=0.000)$ olarak belirlenmiştir. Verim parametreleri ile toprakların kimyasal özellikleri arasındaki pedotransfer modellerin geçerliliğinin belirlenmesinde belirleme katsayısı (R), hata kareler ortalamasının karekökü (HKOK), uygunluk indeksi (d), modelin etkinliği (ME) birlikte değerlendirilmiştir. Deneysel verilere göre elde edilen pedotransfer modellerin geçerliliklerinin belirlenmesinde, modellerin oluşturulmasında kullanılan değerler dışındaki verilerden kullanılmıştır. Elde edilen pedotransfer modellerin, ova topraklarında yetiştirilen soya bitkisinin verim parametrelerinin tahmin edilmesinde uygulanabilirliği mümkün gözükmektedir.

Anahtar Kelimeler: Kimyasal toprak özellikleri, Verim, Bitki boyu, Bin tane ağırlı̆̆ı, Pedotransfer modeller

\footnotetext{
2*Sorumlu Yazar/Corresponding Author: İmanverdi EKBERLİ, Ondokuz Mayıs Üniversitesi, Ziraat Fakültesi Toprak Bilimi ve Bitki Besleme Bölümü, Samsun, Türkiye. E-mail: iman@omu.edu.tr (D) OrcID: 0000-0002-7245-2458

${ }^{1}$ Nalan KARS, T.C. Tarım ve Orman Bakanlığı, Karadeniz Tarımsal Araştırma Enstitüsü Müdürlüğü, Samsun, Türkiye. E-mail: nalan.kars@tarimorman.gov.tr (iD) OrcID: 0000-0002-0609-0815

Atıf/Citation: KARS, N., EKBERLİ, İ. Soya Bitkisinin Verim Parametreleri ile Bazı Kimyasal Toprak Özellikleri Arasındaki Pedotransfer Modellerin Uygulanabilirliği. Tekirdağ Ziraat Fakültesi Dergisi, 18 (3), 494-507.

CBu çalışma Tekirdağ Namık Kemal Üniversitesi tarafından Creative Commons Lisansı (https://creativecommons.org/licenses/by-nc/4.0/) kapsamında yayınlanmıştır. Tekirdağ 2021
} 


\begin{abstract}
The aim of this study was to develop pedotransfer models on the basis of correlation between yield parameters of soybean (plant height, thousand seed weight, and seed yield) and some chemical characteristics of soils and to determine applicability of obtained models in estimation of plant yield grown in soils of Çarşamba Plain. For this purpose, 40 soil and plant samples taken from the fields of the plain where soybean cultivation is carried out by the farmers were analyzed by random sampling method. The values of the yield indices of soybean plant, namely PH, TSW and SY varied between 172.33-351.22 cm, 167.54-450.75 $\mathrm{g}$ and 833.58-1584.37 $\mathrm{kg} \mathrm{da}^{-1}$ respectively. There was a significant correlation $\left(0.476^{*}\right)$ between PH value of soybean plant and TSW, as well as between PH value and copper $(\mathrm{Cu})$ content $(0.484 * *)$ of the soil. A significant positive correlation $(0.384 *$ ve $0.382 *)$ was found seed yield value and potassium $(\mathrm{K})$ and phosphorus $(\mathrm{P})$ contents of the soil. Pedotransfer models between soybean plant height and soil properties of nitrogen $(\mathrm{N}), \mathrm{P}, \mathrm{K}$, organic matter $(\mathrm{OM})$, electrical conductivity (EC), cation exchange capacity $(\mathrm{CEC}), \mathrm{Cu}$, lime $\left(\mathrm{CaCO}_{3}\right)$ high coefficient determination $(\mathrm{R}=0.721)$ and was significant $(\mathrm{p}=0.078)$; Model between thousand seed weight and $\mathrm{EC}, \mathrm{OM}, \mathrm{BD}$, calcium + magnesium $(\mathrm{Ca}+\mathrm{Mg}), \mathrm{N}, \mathrm{P}, \mathrm{K}$, $\mathrm{CaCO}_{3}$, sodium $(\mathrm{Na}), \mathrm{Cu}$, zinc $(\mathrm{Zn})$, resulted in $\mathrm{R}=0.664$ and was insignificant; and model between seed yield and $\mathrm{EC}, \mathrm{CaCO}_{3}, \mathrm{OM}, \mathrm{N}, \mathrm{P}, \mathrm{K}, \mathrm{Zn}, \mathrm{Mn}$ yielded $\mathrm{R}=0.921$ and it was highly significant $(\mathrm{p}=0.000)$. Determination coefficient (R), root mean square error (RMSE), index of agreement (d), model efficiency (ME) were evaluated together to determine the validity of regression models. In determining the validity of the pedotransfer models obtained according to the experimental data, the data except the values used in the creation of the models were used. In general, statistical parameters were within validity limits. The results suggested that the developed regression models can be applied in the estimation of yield parameters in soybean grown in study area.
\end{abstract}

Keywords: Chemical properties of soils, Yield, Plant height, Thousand seed weight, Pedotransfer models 


\section{Giriș}

Tarımsal üretimde birim alandan daha fazla ürün almak için kullanılan kimyasal gübre, toprak düzenleyicileri, endüstriyel ve evsel atıklar, kalitesiz sulama suları vb. faktörler zamanla toprakların fiziksel, kimyasal ve biyolojik özelliklerinde değişmelere sebep olmaktadır. Tarımsal üretimin sürdürülebilir olması, üretimin ana kaynağı olan toprağın korunmasına ve rasyonel kullanılmasına bağlı olup, toprak özelliklerinin optimum düzeyde değişimiyle ilişkili olmaktadır. Toprak özelliklerinin değişimine bağlı olarak bitki veriminin belirlenmesi ve tahmin edilmesinde çeşitli yöntemlerden (tarla ve laboratuvar denemeleri, bilgisayar programları, teorik ve deneysel modeller vb.) kullanılmaktadır. Yerel ve bölgesel düzeyde deneysel olarak daha kolay belirlenebilen fiziksel ve kimyasal toprak özelliklerinin birikimi, deneysel modellerin uygulamasının kolaylığı, pedotransfer modellerinin ekoloji, hidroloji, çeşitli mühendislik dallarında olduğu gibi, tarım alanlarında da yapılmasının gelişimini sağlamıştır.

Toprakların fiziksel ve kimyasal özellikleri toprak oluşum süreçlerine, verimliliğe ve bitki gelişimine önemli düzeyde etki yapmaktadır. Dolayısıyla, toprakların fiziksel ve kimyasal özelliklerinin belirlenmesi verimliliğin korunması, tahmin edilmesi ve artırılmasına yönelik yöntemlerin oluşturulmasında gereklidir (Bayraklı ve ark., 1999; Taban ve ark., 2004; Ekberli ve Dengiz, 2016; 2017; Kars ve Ekberli, 2019). Toprak biliminde toprak özelliklerine ait yeterli düzeyde değerlerin birikimine paralel olarak, pedotransfer modellerin (regresyon modellerin) amaca uygun olarak kullanımı ortaya çıkmıştır. Bu modellerin yardımıyla, karşılıklı etkileşmede olan özelliklerin bir biriyle matematiksel ifadesi; temel toprak özelliklerine bağlı olarak diğer özelliklerin belirlenmesine imkan sağlamaktadır. Pedotransfer fonksiyonlar toprak biliminin birçok alanında (toprağın hidrolik iletkenliğinin ve infiltrasyon katsayısının, hava-su gibi diğer transfer katsayılarının; bitki verimi ve kalite parametrelerinin toprağın elektriksel iletkenliği ile ilişkisinin; bitkinin farklı gelişme dönemlerinde kuraklığın verim ve verim unsurlarına etkisinin belirlenmesinde; toprak mekaniğinde; toprakların fosfat rejiminin tahmini için sorpsiyon ve desorpsiyon eğrisinin hesaplanmasında) yaygın olarak kullanılmaktadır (McBride ve Joosse, 1996; Shein ve Arkhangelskaya, 2006; Huang ve ark., 2014; Gülser ve Candemir, 2014; Dorsey ve Hardy, 2018; Öztürk ve Korkut, 2018; Yegül ve ark., 2019).

Soya fasulyesi (Glycine max L. Merill.) tanesinde bulunan ortalama \%18-20 yağ, \%40 protein, \%30 karbonhidrat, \%5 mineral madde (Ca, Fe, Zn) ve çok sayıda vitamin (A, B1, B2, C, D, E ve K) ile bitkisel yăg sanayisi ve gıda endüstrisinin, küspesi ile de hayvan beslenmesinin önemli bir ham maddesidir (Arığlu, 2000; Unakıtan ve Aydın, 2012.). Karadeniz bölgesinin en önemli tarımsal potansiyeline sahip olan Çarşamba Ovası'nda, soya bitkisinin ekim alanı 659 ha, üretimi 2796 ton ve verimi ise $424 \mathrm{~kg} \mathrm{da}^{-1}$ ' dır (Anonim, 2016). Toprakların fiziksel, kimyasal, biyolojik özellikleri, iklim koşulları, toprak işleme yöntemleri, tohum çeşidi gibi faktörler soya bitkisinin verimliliğine önemli düzeyde etki yapmaktadır. Bölgede çiftçiler tarafından yapılan eki

$\mathrm{m}$ çalışmalarında gerekli tarımsal uygulamaların yapılmaması, toprak yapısının bozulmasına, toprakların besin maddesi yönünden fakirleşmesine ve dolayısıyla bitkilerde verim düşüklüğünün meydana gelmesine sebep olmaktadır. Bu nedenle, ovanın soya yetiştirilen topraklarının fiziksel, kimyasal, biyolojik özelliklerinin dağılımının belirlenmesi; verim ve toprak özellikleri arasındaki pedetransfer modellerin oluşturulması önemli olup, verimin tahmininde kullanılma olanağı sağlamaktadır.

Pedetransfer modellerin geçerliliğinin belirlenmesinde farklı istatiksel parametrelerden kullanılması, model oluşturulmasında önemli ve gerekli aşamalardan biridir. Birçok araştırmacı tarafından pedetransfer fonksiyonların uygulanabilirliğini belirlemek için; hata kareler ortalamasının karekökü (HKOK), uygunluk indeksi (d), maksimum nispi hata $(\mathrm{MNH})$, mutlak hata $(\mathrm{MH})$, belirleme katsayısı $(\mathrm{R})$ gibi istatistiksel parametreler kullanılmıştır (Alexandrov ve Hoogenboom, 2000; To ve Kay, 2005; Budka ve ark., 2015; Ghorbani ve ark., 2015; Cueff ve ark., 2021).

Bu araştırma; Çarşamba Ovası'nda geleneksel toprak işleme yöntemiyle soya yetiştirilen tarım topraklarının bazı kimyasal özellikleri ile soya bitkisinin verim parametreleri arasındaki korelasyon ilişkilere dayanarak, bu özellikler arasında pedotransfer modellerin oluşturulması ve elde edilen modellerin ova topraklarında bitki veriminin tahmininde uygulanabilirliğinin belirlenmesi amacıyla yürütülmüştür. 


\section{Materyal ve Metot}

Araştırma; 2013-2014 yıllarında Samsun ili Çarşamba Ovası'nı temsil eden 20 köyde, çiftçiler tarafından tarım yapılan arazilerden 0-20 cm derinlikten rastgele örnekleme metodu ile Jackson (1962) tarafindan bildirildiği şekilde her yıl için 20 toprak örneği alınarak gerçekleştirilmiştir. Aynı alanlardan bitki örneklerinin alınmasında Anonim (2013)'de gösterilen yöntem kullanılmıştır. Toprak ve bitki örneklerinin alındığı lokasyonlar Şekil 1'de gösterilmiştir.

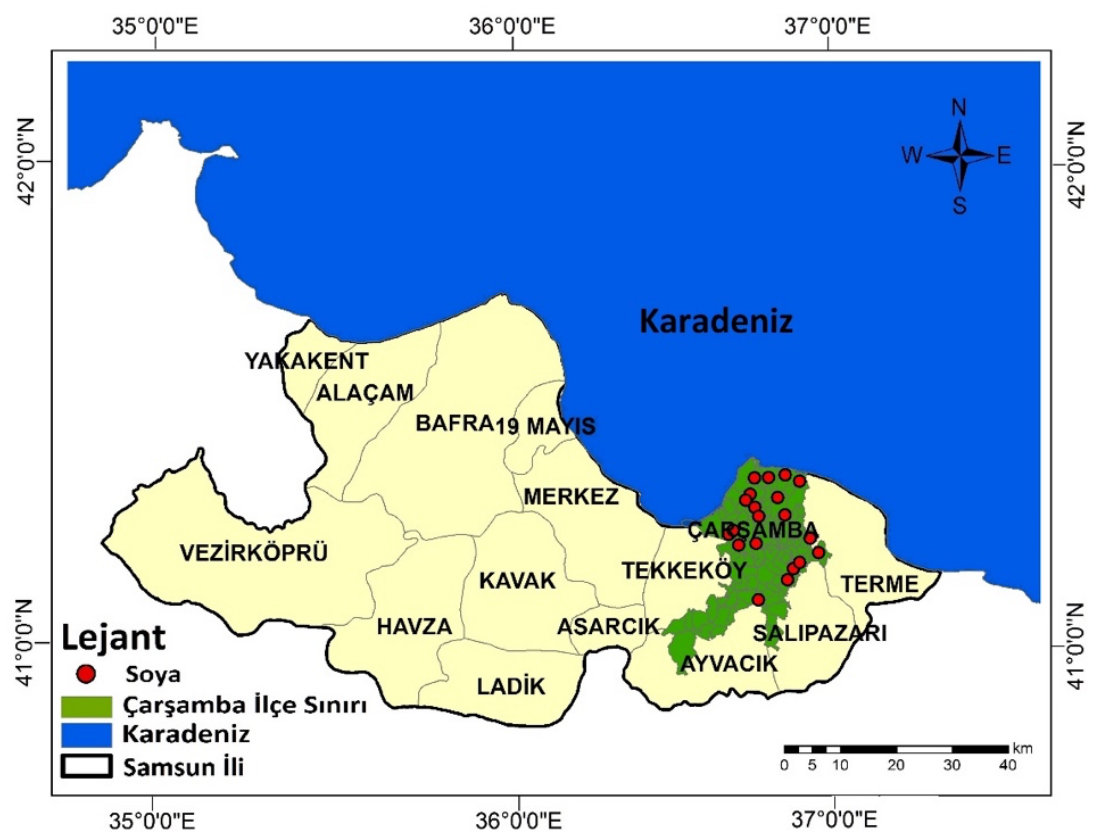

Şekil 1. Araştırma alanının konumu, toprak ve bitki örneklerinin alındı̆̆ı noktalar

Figure 1. Locations where soil and plant samples were taken

Samsun ili sınırları içerisinde yer alan Çarşamba Ovası, güneyde Canik dağları ile kuzeyde ise Karadeniz ile sınırı bulunan Yeşilırmak'ın oluşturduğu bir delta ovasıdır. Ova 0-50 m kotları arasında, 103.766 hektarlık bir alanı kapsamaktadır. Çarşamba Ovası doğu-batı istikametinde $65 \mathrm{~km}$, güney-kuzey istikametinde ise $35 \mathrm{~km}$ uzunluğa sahiptir. Ova taban arazilerinin genel eğimleri güney-kuzey istikametinde olup ortalama eğim \% 0.1 'dir. Bu eğim, deniz kenarına yaklaştıkça \% 0-0.02'ye kadar düşmektedir. Yamaç arazilerde ise eğim, \% 2-40 arasında değişmektedir. Ova; bitki örtüsü yönünden çok zengin olup, 58921 hektar tarım arazisine sahiptir. Ovada soya bitkisi 659 hektar alanda yetiştirilmektedir. Ova toprakları alüviyal ve kısmen de kolüviyal (kestane rengi topraklar, gri-kestane podzolik topraklar, kahverengi orman toprakları) karakterdedir (Anonim, 1984). Ovada yıllık toplam yağış miktarı 985.9 mm olup, yıllık sıcaklık ortalaması ise $15-17^{\circ} \mathrm{C}$ 'dir (Turan ve ark., 2018).

Alınan toprak örneklerinde toprak reaksiyonu $(\mathrm{pH}), 1: 1$ oranında hazırlanan toprak-su süspansiyonunda cam elektrotlu pH metre ile (Bayraklı, 1987); elektriksel iletkenlik (EC), 1:1 oranında hazırlanan toprak-su süspansiyonunda elektriksel kondaktivite aleti ile (Richards, 1954); kireç $\left(\mathrm{CaCO}_{3}\right)$, Scheibler kalsimetresiyle volümetrik olarak (Kacar, 1994); organik madde (OM), Walkley-Black yaş yakma yöntemine göre (Kacar, 1994) ve toplam azot (N) Kjeldahl yaş yakma yöntemine göre (Kacar, 1994) belirlenmiştir. Toprakların yarayışlı fosfor (P) içeriği, mavi renk yöntemine göre (Olsen ve ark., 1954); değişebilir potasyum (K) ve sodyum (Na), toprak örneğinin $1 \mathrm{~N}$ amonyum asetat ( $\mathrm{pH}=7.0)$ çözeltisi ile ekstrakte edilmesiyle, kalsiyum $(\mathrm{Ca})$ ve magnezyum $(\mathrm{Mg})$ 0.01M EDTA titrasyonu ile (Sağlam, 1997); katyon değişim kapasitesi (KDK), Bower yöntemine göre (Anonymous, 1954); alınabilir demir (Fe), bakır (Cu), mangan (Mn) ve çinko (Zn) içerikleri ise Lindsay ve Norvell (1978) tarafından bildirildiği şekli ile (0.005 M DTPA + 0.01 $\left.\mathrm{M} \mathrm{CaCI}_{2}+0.1 \mathrm{M} \mathrm{TEA}, \mathrm{pH}=7.3\right)$ tespit edilmiştir. Soya bitkisinde bitki boyu (BB), bin tane ağırlığı (BTA) ve tane verimi (TV) ölçümleri, Anonim (2013) tarafından bildirilen esaslar çerçevesinde yapılmıştır. 
Toprak ve bitki analiz sonuçlarına ait tanımlayıcı istatistikler ile toprak özellikleri ve bitki agronomik parametreleri arasındaki korelasyonlar SPSS 17.0 paket programında hesaplanmış, agronomik parametreleri ile toprak özellikleri arasında oluşturulan regresyon modeller ise, Minitab 17.0 paket programında oluşturulmuştur.

Hata kareler ortalamasının karekökü (HKOK), uygunluk indeksi (d) ve model etkinliği (ME) sırasıyla aşağıdaki eşitlikler kullanılarak hesaplanmıştır:

$$
H K O K=\sqrt{\frac{1}{n_{i=1}} \sum_{i}^{n}\left(x_{i}-y_{i}\right)^{2}}
$$

Eşitlik 1'de, $n$-verilerin sayı ve $n<30$ ise $m=n-1, n>30$ ise $m=n ; x_{i}$ - ölçülen; $y_{i}$ - hesaplanan değerlerdir.

$$
\begin{gathered}
d=1-\frac{\sum_{i=1}^{n}\left(x_{i}-y_{i}\right)^{2}}{\sum_{i=1}^{n}\left(\left|x_{i}-\bar{y}\right|+\left|y_{i}-\bar{y}\right|\right)^{2}} \\
M E=1-\frac{\sum_{i=1}^{n}\left(x_{i}-y_{i}\right)^{2}}{\sum_{i=1}^{n}\left(y_{i}-\bar{y}\right)^{2}}
\end{gathered}
$$

Eşitlik 2 ve 3'de, $\bar{y}$ hesaplanan değerlerin ortalamasını ifade etmektedir.

Hata kareler ortalamasının karekökü (HKOK), tahmin hatalarının standart sapmasını ifade etmektedir. Uygunluk indeksi $(d)$ modelin geçerliliğinin bir göstergesi olup, $d$ 'nin 1'e yakın olması modelin uygulanabilirliğini göstermektedir. Krause ve ark. (2005) tarafından, deneysel hidrolojik modele yönelik bir araştırmada, ME değerlerinin 1 (mükemmel uyum) ile - $-\infty$ arasında değiştiği gösterilmiş; ME'nin sıfırdan küçük olması durumunda ise ölçülen ortalama değerin, hesaplanan değerden daha etkin olduğu belirtilmiştir. $d$ ve ME’nin analitik ifadelerinin karşılaştırılmasından da görüldüğü gibi, genel olarak $d$ ME'den daha büyük değerler almaktadır (Willmott ve Matsuura, 2005; Willmott ve ark., 2012; Kumar ve ark., 2015).

\section{Araştırma Sonuçları ve Tartışma}

\subsection{Soyanın verim parametreleri}

Araştırma alanında yetiştirilen soyanın bazı verim parametrelerine ilişkin tanımlayıcı istatistikler Tablo l'de verilmiştir.

Tablo 1. Soyanın bazı verim parametrelerine ilişkin bazı tanımlayıcı istatistikler (n=40)

Table 1. Some descriptive statistics of some yield parameters of soybean plant $(n=40)$

\begin{tabular}{lcccccc}
\hline Özellikler & En düşük & En yüksek & Ortalama & Standart sapma & $V K, \%$ & Çarpıklık \\
\hline BB, cm & 88.33 & 127.27 & 103.31 & 9.91 & 9.59 & 1.127 \\
BTA, g & 164.10 & 242.91 & 200.54 & 17.81 & 8.88 & 0.505 \\
TV, $\mathrm{kg} \mathrm{da}^{-1}$ & 280.32 & 593.16 & 455.87 & 81.71 & 17.92 & -0.410 \\
\hline
\end{tabular}

BB: Bitki boyu, BTA: Bin tane ağırlı̆̆ı, TV: Tane verimi, $V K$ : Varyasyon katsayısı.

Tablo 1'den görüldüğü gibi, soya bitkisinin BB, BTA ve TV değerleri sırasıyla; 88.33-127.27 cm, 164.10$242.91 \mathrm{~g}$ ve $280.32-593.16 \mathrm{~kg} \mathrm{da}^{-1}$ arasında değişmekte, ortalama değerleri ise sırasıyla $103.31 \mathrm{~cm}, 200.54 \mathrm{~g}$ ve 
$455.87 \mathrm{~kg} \mathrm{da}^{-1}$ olmaktadır. Görüldüğü gibi, istatistiksel göstergeler geçerli sınırlar (Willmott ve Matsuura, 2005) dahilinde değişmektedir. Bitki boyu ve bin tane ağırlığına ait standart sapma değerleriyle karşılaştırıldığında tane veriminin standart sapmasının yüksek olmasının nedeni, tane veriminin geniş aralıkta değişimi olabilir. Varyasyon katsayısı $(<20)$ ise verilerin homojen dağılıma sahip olduğunu göstermektedir. Çarpıklık değerleri ise, sağdan ve soldan sıfıra yakın olmakta, dolayısıyla dağılımın genel olarak normale yakın olduğunu göstermektedir.

Soya bitkisi, dünyadaki en önemli baklagil bitkilerinden biridir. Soyada verim ve verim bileşenlerini etkileyen en önemli faktörlerin başında çeşit seçimi ve kullanılan tohumun kalitesi gelmektedir (Yetkin ve Arığlu, 2009). Soyada bitki boyu; çeşit, ekim sıklığı, ekim zamanı ve yetiştirme şartlarına bağl olarak, $30-150 \mathrm{~cm}$ arasında değişim göstermektedir (Arığlu, 2000). Homer ve ark. (2000), Karadeniz Bölgesinin sahil ve geçit bölgelerine uygun soya çeşitlerini belirlemek ve geliştirmek amacıyla yapmış oldukları bir çalışmada, bitki boylarının 72.9 $\mathrm{cm}$ ile $128.8 \mathrm{~cm}$ arasında, bin tane ağırlığın $157.0 \mathrm{~g}$ ile $298.0 \mathrm{~g}$ arasında değiştiğini bildirmişlerdir. Soya verimini esas olarak tane ağırlı̆̆ ve tane sayısı belirlemekte ve tane sayısı birim alandaki bakla sayısına ve bakladaki tane sayısına bağlı olmaktadır (Karagül ve ark., 2011). Ay (2012) tarafından, Türkiye'de ıslah edilmiş yeni soya (Glycine max. 1. merrill) çeşitlerinin Orta Karadeniz Bölgesi koşullarında verim ve kalite performanslarının belirlendiği bir çalışmada, Terme'de en yüksek tane veriminin $570.68 \mathrm{~kg} \mathrm{da}^{-1}$ ile Erensoy çeşidinde; en düşük tane verimin ise $335.50 \mathrm{~kg} \mathrm{da}^{-1}$ ile Üstün 1 çeşidinden elde edildiği bildirilmiştir.

\subsection{Soya tarımı yapılan toprakların kimyasal özelliklerinin değişimi}

Ovada soya yetiştirilen toprakların bazı kimyasal özelliklerine ait tanımlayıcı istatistikler Tablo 2'de verilmiştir.

Tablo 2. Soya bitkisi yetiştirilen toprakların bazı kimyasal özelliklerine ait bazı tanımlayıcı istatistikler

Table 2. Some descriptive statistics of some chemical properties of soils grown in soybean plants $(n=40)$

\begin{tabular}{|c|c|c|c|c|c|c|}
\hline Özellikler & En düşük & En yüksek & Ortalama & Standart Sapma & $\mathrm{VK}, \%$ & Çarpıklık \\
\hline $\mathrm{pH},(1: 1)$ & 7.00 & 8.02 & 7.72 & 0.21 & 2.72 & -1.566 \\
\hline $\mathrm{EC}, \mathrm{dS} \mathrm{m}^{-1}(1: 1)$ & 0.40 & 0.98 & 0.60 & 0.14 & 23.33 & 0.881 \\
\hline $\mathrm{CaCO}_{3}, \%$ & 0.55 & 13.45 & 5.84 & 4.08 & 69.86 & 0.154 \\
\hline OM, \% & 1.61 & 5.05 & 2.89 & 1.03 & 35.64 & 0.724 \\
\hline $\mathrm{N}, \%$ & 0.11 & 0.30 & 0.15 & 0.04 & 26.66 & 1.571 \\
\hline $\mathrm{P}, \mathrm{ppm}$ & 1.74 & 38.26 & 13.68 & 10.08 & 73.68 & 0.890 \\
\hline $\mathrm{K}, \mathrm{cmol} \mathrm{kg}{ }^{-1}$ & 0.17 & 1.17 & 0.56 & 0.20 & 35.71 & 0.783 \\
\hline $\mathrm{Ca}+\mathrm{Mg}, \mathrm{cmol} \mathrm{kg}{ }^{-1}$ & 29.03 & 94.39 & 50.52 & 17.02 & 308.33 & 0.692 \\
\hline $\mathrm{Na}, \mathrm{cmol} \mathrm{kg}^{-1}$ & 0.35 & 2.46 & 1.37 & 0.70 & 51.09 & -0.346 \\
\hline $\mathrm{KDK}, \mathrm{cmol} \mathrm{kg}{ }^{-1}$ & 30.05 & 96.96 & 52.47 & 17.30 & 32.97 & 0.693 \\
\hline $\mathrm{Fe}, \mathrm{ppm}$ & 21.99 & 60.74 & 33.85 & 9.65 & 28.50 & 0.858 \\
\hline Mn, ppm & 4.95 & 31.49 & 11.68 & 5.27 & 45.11 & 2.679 \\
\hline $\mathrm{Cu}, \mathrm{ppm}$ & 2.27 & 9.37 & 5.81 & 1.61 & 27.71 & 0.031 \\
\hline $\mathrm{Zn}, \mathrm{ppm}$ & 0.29 & 1.26 & 0.58 & 0.19 & 32.75 & 1.503 \\
\hline
\end{tabular}

H: Toprak reaksiyonu; EC: Elektriksel iletkenlik; $\mathrm{CaCO}_{3}$ : Kireç; OM: Organik madde; N: Azot; P: Fosfor; K: Potasyum; Ca+Mg: Kalsiyum+Magnezyum; Na: Sodyum; KDK: Katyon değişim kapasitesi; Fe: Demir; Mn: Mangan; Cu: Bakır; Zn: Çinko; VK: Varyasyon katsayısı.

Tablo 2'den görüldüğü gibi, soya yetiştirilen topraklar genellikle nötr ile hafif alkalin reaksiyonlu, tuzsuz, kireçsiz ile orta kireçli ve organik madde içeriği orta düzeyde belirlenmiştir. Toprakların azot miktarı genellikle orta, fosfor kapsamı çoğunlukla az ve iyi, potasyum kapsamı çoğunlukla orta düzeyde saptanmıştır. Topraklardaki KDK miktarı genellikle yüksek ve çok yüksek arasaında, sodyum miktarı orta ile yüksek arasında, demir kapsamı çoğunlukla orta ile yüksek arasında değişmekte, mangan kapsamı genellikle düşük düzeyde, bakır kapsamı çok yüksek, çinko kapsamı çoğunlukla çok düşük düzeyde belirlenmiştir. Toprakların kimyasal özelliklerine ait tanımlayıcı istatistik değerleri ise genel olarak güvenirlilik sınırları dahilinde olup, normala yakın dağılım göstermektedir. Kültivasyon işlemleri ile organik madde, kireç, gübre ve sentetik toprak düzenleyicilerinin toprağa ilavesi gibi antropojenik etkiler toprak özelliklerinin $\left(\mathrm{P}, \mathrm{CaCO}_{3}, \mathrm{Ca}+\mathrm{Mg}\right)$ geniş aralıkta değişimine, dolayısıyla değerlerin heterojen dağılımına ve varyasyon katsayılarının yüksek olmasına sebep olabilmektedir. 


\subsection{Soya bitkisinin bazı verim parametreleri ile toprağın bazı kimyasal özellikleri arasındaki ilişkiler}

Soya bitkisinin verim parametreleri ile toprağın bazı kimyasal parametrelerine ait korelasyon katsayıları (r) Tablo 3’te verilmiştir.

Tablo 3. Soya bitkisinin bazı verim parametreleri ile toprağın kimyasal özelliklerine ilişkin korelasyon matrisi

Table 3. Correlation matrix for some yield parameters of soybean plant and chemical properties of soil

\begin{tabular}{lccc}
\hline Özellikler & BB, cm & BTA, g & TV, $\mathrm{kg} \mathrm{da}^{-1}$ \\
\hline $\mathrm{BB}, \mathrm{cm}$ & 1 & & \\
$\mathrm{BTA}, \mathrm{g}$ & $0.476^{*}$ & 1 & \\
$\mathrm{TV}, \mathrm{kg} \mathrm{da}^{-1}$ & 0.199 & 0.131 & 1 \\
$\mathrm{pH},(1: 1)$ & 0.017 & -0.137 & 0.115 \\
$\mathrm{EC}, \mathrm{dS} \mathrm{m}^{-1}(1: 1)$ & 0.194 & 0.181 & 0.307 \\
$\mathrm{CaCO}, \%$ & 0.266 & 0.182 & -0.070 \\
$\mathrm{OM}, \%$ & 0.059 & 0.321 & 0.140 \\
$\mathrm{~N}, \%$ & 0.189 & 0.328 & 0.336 \\
$\mathrm{P}, \mathrm{ppm}$ & 0.172 & 0.258 & $0.382^{*}$ \\
$\mathrm{~K}, \mathrm{cmol} \mathrm{kg}$ & 0.321 & 0.142 & $0.384^{*}$ \\
$\mathrm{Ca}+\mathrm{Mg}^{-1} \mathrm{cmol} \mathrm{kg}^{-1}$ & 0.213 & 0.267 & 0.004 \\
$\mathrm{Na}, \mathrm{cmol} \mathrm{kg}$ & 0.000 & $0.389^{*}$ & -0.347 \\
$\mathrm{KDK}, \mathrm{cmol} \mathrm{kg}{ }^{-1}$ & 0.213 & 0.280 & -0.006 \\
$\mathrm{Fe}, \mathrm{ppm}$ & 0.101 & -0.090 & -0.004 \\
$\mathrm{Mn}, \mathrm{ppm}$ & -0.339 & -0.108 & -0.365 \\
$\mathrm{Cu}, \mathrm{ppm}$ & $0.484^{* *}$ & 0.230 & 0.273 \\
$\mathrm{Zn}, \mathrm{ppm}$ & -0.026 & 0.275 & -0.254 \\
\hline
\end{tabular}

** $\mathrm{p} \leq 0.01$ hata düzeyinde çok önemli, ${ }^{*} \mathrm{p} \leq 0.05$ hata düzeyinde önemli

Soya BB değeriyle BTA'ı arasında önemli pozitif $\left(0.476^{*}\right)$; BB ile topraklardaki Cu miktarı arasında ise çok önemli pozitif ilişkiler $\left(0.484^{* *}\right)$ belirlenmiştir. Ersoy ve Arıoğlu (1988), bitki boyu ve 1000 tane ağırlığı arasında olumsuz bir ilişkinin olduğunu bildirmişlerdir. Soya bitkisi TV değeri ile topraklardaki K ve P miktarları arasında önemli pozitif ilişkiler $(0.384 *$ ve $0.382 *)$ saptanmıştır. Topraklarda fosfor noksanlığının verim üzerinde önemli bir etkisi olduğu araştırmacılar tarafından bildirilmiştir (Chien ve Menon 1995; Fageria ve ark., 2013a; Moreira ve ark., 2017). Soya bitkisi BTA'ı ve toprakların Na içeriği arasında önemli pozitif ilişki $\left(0.389^{*}\right)$ belirlenmiştir. Soya bitkisinin verim parametreleriyle, toprakların diğer kimyasal parametreleri arasında ise istatistiksel açıdan önemli bir ilişki saptanmamıştır. Soya bitkisinin tane verimi üzerine, bakla sayısı doğrudan etkiye sahip olmakta; tane verimi ve 100 tane ağırlığı arasında önemli derecede yüksek ve pozitif ilişki bulunmaktadır (Rajput ve ark., 1987). Çetin (2010), soya bitkisinin verim ve bazı kalite özelliklerine ait bir araştırmada, fosforun bitki boyu üzerine etkisini önemli bulurken, bin tane ağırllğı üzerine etkisini ise önemsiz bulmuştur. Arslanoğlu ve ark. (2005), Karadeniz Bölgesi’nde 2 yıl süreyle yürüttükleri farklı farklı olgunlaşma süresine sahip soya çeşitlerinin verim potansiyellerinin belirlendiği araştırmada; dekara verim ile bitki boyu arasında pozitif önemli ilişki bulmuşlardır. Tayyar ve Gül (2007) tarafından yapılan bir araştırmada, iki yıllık deneme sonuçlarına göre verim ile bitki boyu arasında $\left(\mathrm{r}=0.30^{* *}\right)$ pozitif önemli bir ilişki saptanmıştır

\subsection{Soyanın verim parametreleri ile toprakların bazı kimyasal özellikleri arasındaki pedotransfer modeller}

Soya bitki boyu, bin tane ağırlığı ve tane verimi ile toprakların bazı kimyasal özellikleri arasındaki pedotransfer modeller Tablo 4'de verilmiştir. Pedotransfer modellerinin oluşturulmasında verim parametreleri ile toprakların bazı kimyasal özelliklerine ilişkin korelasyon analiz sonuçları (Tablo 3) dikkate alınmıştır.

Soya bitki boyu ile toprakların bazı kimyasal özellikleri arasındaki (1)-(3) pedotransfer modellerinden (Tablo 4) görüldüğg̈ gibi, regresyon katsayıları 0.539 ile $0.721 ; \mathrm{F}$ değerleri 2.17 ile 3.38 ; p değerleri ise 0.026 ile 0.083 arasında değişmektedir. F değeri etkileşim ve ana etkenlerin anlamlı olup olmadığını belirlemek için yapılmakta, p değeri azaldıkça F'nin değeri artmaktadır. $\mathrm{CaCO}_{3}, \mathrm{OM}, \mathrm{KDK}, \mathrm{Cu}, \mathrm{N}, \mathrm{P}, \mathrm{K}$ parametrelerini ve bu parametre değerlerinin karesini, çarpımını, karekökünü de kapsayan 3. modelde belirleme katsayısı en yüksek ( $\mathrm{R}=0.721)$; $\mathrm{KDK}, \mathrm{EC}, \mathrm{CaCO}_{3}, \mathrm{OM}$ içeren 1. modelde ise en düşük $(\mathrm{R}=0.539)$ saptanmıştır. $\mathrm{p}$ değerlerine göre her iki modelde istatistiksel olarak anlamlılık $(\mathrm{p}<0.10)$ eğilimi dahilinde bulunmuştur. BTA ile toprakların bazı kimyasal özellikleri arasındaki modellerin regresyon katsayıları 0.538 ile 0.664 arasında değişmektedir. Soya bin tane 
ağıllı̆̆ ile toprakların bazı kimyasal özellikleri arasında istatistiksel olarak anlamlı farklılık saptanmamasına rağmen, 6. modelde belirleme katsayısı $(\mathrm{R}=0.664)$ yüksek düzeyde saptanmıştır. Elde edilen regresyon ilişkilerinde toprak özelliklerinin farklı biçimlerde nicel olarak dahil edilmesi modellerin performansını yükseltmiştir.

Tablo 4. Soya bitki boyu, bin tane ağırlı̆̆ı ve tane verimi ile toprakların bazı kimyasal özellikleri arasındaki pedotransfer modeller

Table 4. Pedotransfer models between soybean plant height, thousand seed weight, seed yield and some chemical characteristics of soils

\begin{tabular}{|c|c|c|c|c|}
\hline & Modeller & $\mathrm{R}$ & $\mathrm{F}$ & $\mathrm{p}$ \\
\hline 1. & $\mathrm{BB}=78.5+0.383 \mathrm{KDK}+13.8 \mathrm{EC}+1.20 \mathrm{CaCO}_{3}-3.69 \mathrm{OM}$ & 0.539 & 2.36 & 0.083 \\
\hline 2. & $\mathrm{BB}=213-0.665 \sqrt{K D K \times E C \times O M}-636 \sqrt{N}+798 \mathrm{~N}+3.68 \mathrm{Cu}$ & 0.608 & 3.38 & 0.026 \\
\hline 3. & $\begin{array}{l}\mathrm{BB}=228+937 \mathrm{~N}-0.077 \mathrm{P}+13.3 \mathrm{~K}+0.15 \sqrt{K D K \times E C \times O M}+1.63 \mathrm{Cu} \\
+0.0443(\mathrm{CaCO} 3)^{2}+0.00238(\mathrm{KDK})^{2}-0.766(\mathrm{OM})^{2}-743 \sqrt{N}\end{array}$ & 0.721 & 2.17 & 0.078 \\
\hline 4. & $\begin{array}{l}\mathrm{BTA}=184+58.3 \mathrm{EC}-43.4 \mathrm{OM}+0.693 \mathrm{KDK}-0.241(\mathrm{KDK} \times \mathrm{EC} \times \mathrm{OM}) \\
+7.63 \mathrm{Na}+105 \mathrm{~N}+7.35(\mathrm{OM})^{2}\end{array}$ & 0.538 & 1.17 & 0.364 \\
\hline 5. & $\begin{array}{l}\mathrm{BTA}=536+0.594 \mathrm{KDK}+23.3 \mathrm{EC}+0.77 \mathrm{CaCO}_{3}-4.3 \mathrm{OM}+1.28(\mathrm{OM})^{2} \\
-1780 \sqrt{N}+2085 \mathrm{~N}+0.211 \mathrm{P}-1.42 \mathrm{Cu}-0.067(\mathrm{KDK} \times \mathrm{EC} \times \mathrm{OM})\end{array}$ & 0.601 & 0.96 & 0.509 \\
\hline 6. & $\begin{array}{l}\mathrm{BTA}=541+0.00350(\mathrm{KDK})^{2}+12.3(\mathrm{EC})^{2}+0.60(\mathrm{OM})^{2}-1741 \sqrt{N} \\
+2020 \mathrm{~N}-1.85 \mathrm{Cu}-0.43 \mathrm{Na}+19.3 \mathrm{Zn}+0.111\left(\mathrm{CaCO}_{3}\right)^{2}\end{array}$ & 0.664 & 1.58 & 0.195 \\
\hline 7. & $\mathrm{TV}=270-$ & 0.609 & 2.60 & 0.054 \\
\hline 8 . & $\begin{array}{l}\mathrm{TV}=331-42.9 \mathrm{OM}-37 \mathrm{EC}-6.21 \mathrm{CaCO}_{3}+1472 \mathrm{~N}+1.45 \mathrm{P}+168 \mathrm{~K} \\
+13.4 \mathrm{Cu}-237 \mathrm{Zn}+1.91 \mathrm{Mn}\end{array}$ & 0.776 & 3.03 & 0.022 \\
\hline 9. & $\begin{array}{l}\mathrm{TV}=875-1019 \mathrm{EC}-16.1 \mathrm{CaCO}_{3}-397 \mathrm{OM}+2595 \mathrm{~N}+14.6 \mathrm{P}+754 \mathrm{~K} \\
+57.7(\mathrm{OM})^{2}+790(\mathrm{EC})^{2}+0.339\left(\mathrm{CaCO}_{3}\right)^{2}-185 \mathrm{Zn}+6.09 \mathrm{Mn} \\
-402 \sqrt{(N \times P \times K)}\end{array}$ & 0.921 & 7.05 & 0.000 \\
\hline
\end{tabular}

BB: Soya bitki boyu, cm; BTA: Soya bin tane ağırlığı $\mathrm{g}$; TV: Soya tane verimi, $\mathrm{kg} \mathrm{da}^{-1}$; EC: Elektriksel iletkenlik, $\mathrm{dS} \mathrm{m}^{-1}$; KDK: Katyon değişim kapasitesi, cmol kg-1 OM: Organik madde, \%; N: Azot, \%; P: Fosfor, ppm; K: Potasyum, cmol kg-1; $\mathrm{Cu}$ : Bakır, ppm; $\mathrm{CaCO}_{3}$ : Kireç, \%; Na: Sodyum, cmol kg ${ }^{-1}$; Mn: Mangan, ppm; Zn: Çinko, ppm.

Yapılan araştırmalar, pedotransfer modellerinin toprak özelliklerinin karesi, karekökü ve çarpımını kapsayan polinomlarla ifadesinin, belirleme katsayısını, dolayısıyla tahminin önem düzeyini yükselttiğini göstermektedir (Kosheleva ve ark., 2002; Gülser ve Candemir, 2014; Kars ve Ekberli, 2020). Soya tane verimi ile toprakların EC, $\mathrm{OM}, \mathrm{CaCO}_{3}, \mathrm{~N}, \mathrm{P}, \mathrm{K}, \mathrm{Cu}, \mathrm{Zn}$ gibi kimyasal özellikleri arasında oluşturulan pedotransfer modellerinde regresyon katsayıları 0.609 ile 0.921 ; F değerleri 2.60 ile 7.05 arasında, p değerleri ise 0.000 ile 0.054 arasındadır (Tablo 4). En yüksek belirleme katsayısı $(\mathrm{R}=0.921) 9$. model olup çok yüksek istatistiksel anlamlılık $(\mathrm{p}<0.001)$ düzeyinde bulunmuştur. Murty (2002) yaptığı bir araştırmada, meteorolojik parametreler ile soya bitkisinin bitki boyu, 100 tane ağırlığ 1 ve tane verimi arasında pedotransfer modelleri oluşturmuştur. Araştırmacı, bitki boyu, 100 tane ağırlığı ve tane verim modelleri için çoklu regresyon katsayı $\left(\mathrm{R}^{2}\right)$ değerlerini sırasıyla $0.97 ; 0.93 ; 0.93$ olarak saptamıştır. Ovando ve ark. (2018) soyada tane verimini tahmin etmek için; solar radyosyon ve yağış değerleri ile toprakların kimyasal ve fiziksel özelliklerini kullanarak pedotransfer modelleri oluşturmuşlar ve en yüksek belirleme katsayı $\left(\mathrm{R}^{2}\right)$ değerini 0.849 olarak hesaplamışlardır. Fageria ve ark. (2013b) tarafından, kirecin soya verimi ve verim unsurları üzerine yaptıkları bir araştırmada, verim ile toprağın kimyasal özellikleri arasındaki ilişkilerin belirlenmesinde $\mathrm{Y}=\mathrm{f}(\mathrm{x})$ biçiminde ikinci dereceden regresyon denklemlerinden kullanılmış, belirleme katsayılarını 0.863 ile 0.522 arasında değiştiğini ve \%1 olasılık düzeyinde anlamlı bulunmuştur.

\subsection{Verim Parametreleri ile Toprak Özellikleri Arasında Oluşturulan Pedotransfer Modellerin Geçerlilikleri}

Deneysel verilere göre elde edilen pedotransfer modellerin geçerliliklerinin belirlenmesinde, modellerin oluşturulmasında kullanılan değerler dışındaki veya veri bankasındaki değerlerden kullanılması gerekmektedir (Wang ve ark., 2016). Soya bitkisinin BB, BTA ve TV ile toprakların bazı kimyasal özellikleri arasındaki pedotransfer modellerinin geçerliliğinin belirlenmesine ait istatistiksel parametreler Tablo 5'te verilmiştir. 
Soya Bitkisinin Verim Parametreleri ile Bazı Kimyasal Toprak Özellikleri Arasındaki Pedotransfer Modellerin Uygulanabilirliği

Tablo 5. Soya bitki boyu (BB), bin tane ağırlı̆̆ı (BTA) ve tane verimine (TV) ait pedotransfer modellerin bazı istatistiksel parametreleri

Table 5. Some statistical parameters of pedotransfer models of maize plant height, thousand seed weight and seed yield

\begin{tabular}{lcccc}
\hline Modeller (No) & R & HKOK & $d$ & ME \\
\hline BB (3) & 0.721 & 6.627 & 0.984 & -0.167 \\
BTA (6) & 0.664 & 6.845 & 0.995 & 0.648 \\
TV (9) & 0.921 & 34.201 & 0.997 & 0.794 \\
\hline
\end{tabular}

BB: Bitki boyu, BTA: Bin tane ağırlığı, TV: Tane verimi, R: Belirleme katsayısı, HKOK: Hata kareler ortalamasının karekökü, d: Uygunluk indeksi, ME: Modelin etkinliği.

Tablo 5'ten görüldüğg̈ gibi, modelin uygunluk indeksi (d) 1'e yakın, modelin etkinliği 1'den büyük olmakta, hata kareler ortalamasını karekökü ise yüksek olmamakta, aynı zamanda $d$ değerleri ME'den büyük olmaktadır. $\mathrm{Bu}$ nedenle, pedotransfer modellerine ait istatistiksel göstergeler genel olarak, geçerlilik sınırları dahilinde değişmektedir (Krause ve ark., 2005; Wang ve ark., 2016). Sentelhas ve ark. (2015) tarafindan Brazilya'nın her bir bölgesindeki soya tane verim tahmini için olușturulan modelin d değeri 0.87 olarak belirlenmiștir. Ovado ve ark. (2018) Arjantin soya yetiștirilen topraklarında 2006-2016 yılları arasında yürüttükleri çalıșmalarında, iklim verilerine bağlı olarak soya verimi tahmini için kulladıkları modelde belirleme katsayısını 0.849 olarak saptamışlardır. Kumar ve ark. (2008) tarafindan yapılan bir araștırmada, farklı 3 çeșit soya bitkisinin tane verimlerinin tahmini için kullandıkları modele ait HKOK değerlerini sırasıyla $86.0 \mathrm{~kg} \mathrm{ha}^{-1}, 123.9 \mathrm{~kg} \mathrm{ha}^{-1} ; 28.6 \mathrm{~kg}$ ha ${ }^{-1}$ olarak hesaplanmışlardır.

Pedotransfer modellerin yapılmasındaki bazı sınırlamalara rağmen, modelin yapılmasının ve uygulamasının kolay olması araştırmacılar için avantaj sağlamakta (Tamari ve ark., 1996; Schaap ve ark., 2001) ve aynı zamanda modellerinin toprak özelliklerine, çevresel değişkenlere bağlı olarak toprak özelliklerinin mekânsal değişimine dayanan sınıflandırması da söz konusu olmaktadır (Minasny ve McBratney, 2008).

Soya bitki boyu, bin tane ağırlığı, tane veriminin üçüncü modele göre hesaplanan ve ölçülen değerlerin karşılaştırılması Şekil 2'de verilmiştir. Soya BB, BTA, TV ile toprakların kimyasal özellikleri arasındaki pedotransfer modellere göre hesaplanan ve ölçülen değerler arasındaki korelasyon değerleri sırasıyla $0.762,0.802$ ve 0.753 olup, 0.01 düzeyinde istatistiksel olarak anlamlı bulunmuştur.

Şaylan (1996) tarafından soya bitkisinin gelişimi ve veriminin tahmin edilmesine ait yapılan bir modelleme araştırılmasında, hesaplanan verimin gerçek verimden \%14.6 düzeyinde daha yüksek olduğu saptanmıştır. Araştırıcı, bu farklılığın, modelin deneme alanına göre düzenlenmemesinden kaynaklanabileceğini bildirmiştir. Bhatia ve ark. (2008), soya yetiştirilen alanlardan alınan 21 adet toprak örneklerinde yaptıkları analiz sonuçlarına bağlı olarak, soya bitkisinin verimini tahmin etmek için kullandıkları modelde, soya verimini $2170 \mathrm{~kg} \mathrm{ha}^{-1}$, bu alanlardaki gerçek verim ortalamasının $1000 \mathrm{~kg} \mathrm{ha}^{-1}$ olduğunu bildirmişlerdir. Su sınırlaması varsayımında model yardımıyla hesaplanan soya verimi ile çiftçilerin elde ettiği gerçek verim değerleri arasındaki farkın, ürünün yetiştiği mevsimdeki yağış miktarı düşük olduğunda azaldığını, yağış miktarı artığında ise önemli derecede arttığını bildirmişlerdir. 


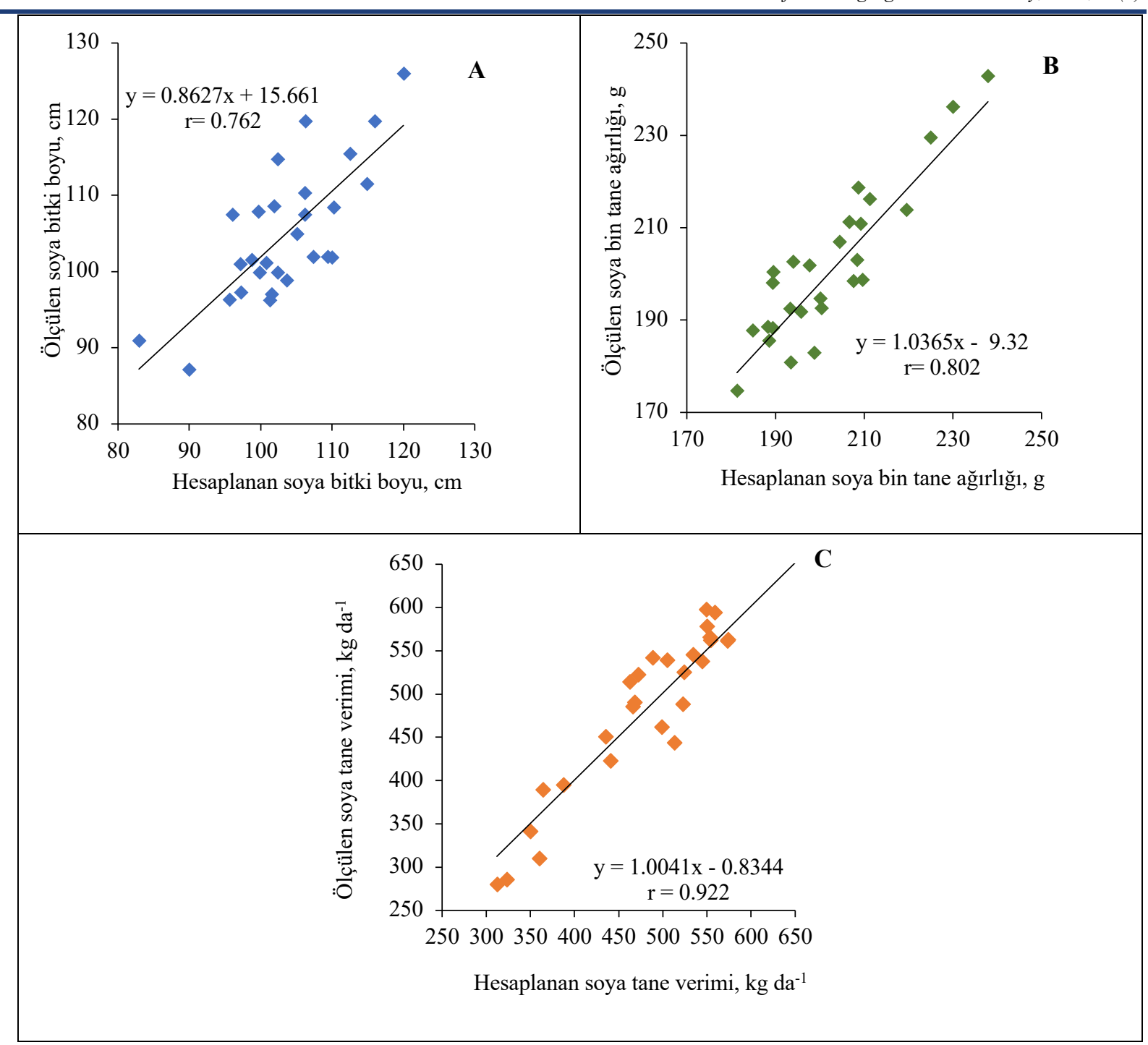

Şekil 2. Soya bitki boyu (A), bin tane ăğırlı̆̆ (B), tane veriminin (C) hesaplanan ve ölçülen değerler arasındaki iliş̧i

Figure 2. The relationship between calculated and measured plant height (A), thousand seed weight (B), seed yield $(C)$

\section{Sonuç}

Toprakların fiziksel, kimyasal ve biyolojik özelliklerinin değişimi, bitki verimine önemli düzeyde etki yapan faktörlerden biridir. Çarşamba Ovasında geleneksel toprak işleme yöntemleriyle ana ürün olarak soya bitkisi yetiştirilen tarım alanlarının bazı kimyasal özellikleri ve soya bitkisinin verim parametreleri belirlenmiş; bu özellikler arasındaki korelasyon ilişkiler saptanmış ve bitkilerin bazı verim unsurları ile toprakların bazı kimyasal özellikleri arasında pedotransfer modelleri oluşturulmuştur. Oluşturulan pedotransfer modellerin toprak özellikleri değerlerinin çarpımını, karesini ve karekökünü içeren çok terimli ile ifade edilmesi, belirleme katsayısının yükselmesine ekti yapan faktördür. Ölçülen ve pedotransfer modellerine göre hesaplanan verim parametrelerinin karşılaştırılması; elde edilen pedotransfer modellerin araştırma bölgesinin soya yetiştirilen topraklarında verim parametrelerinin tahmini için uygulanabilirliğini göstermiş̧tir. Soya bitkisinin tane verimi ile toprağın $\mathrm{CaCO}_{3}, \mathrm{OM}$, $\mathrm{N}, \mathrm{P}, \mathrm{K},(\mathrm{OM})^{2},(\mathrm{EC})^{2},\left(\mathrm{CaCO}_{3}\right)^{2}, \mathrm{Zn}, \mathrm{Mn}, \sqrt{(N \times P \times K)}$ parametreleri arasındaki model en yüksek performansa sahip olmaktadır. Bu modellerin daha yüksek düzeydeki başarısı, soya bitkisinin optimum verim seviyesine sahip olduğu alanlarda yapılacak çalışmalara bağlıdır. Tarımsal ve çevresel faktörleri ile daha çok sayıda toprak ve bitki verilerinin modellere dahil edilmesiyle tahmin sonuçlarının daha iyi olabileceği düşünülmektedir. Pedotransfer modellerin oluşturulmasının ve uygulanmasının kolaylı̆̆ı dikkate alınarak, yerel ve bölgesel düzeyde çeşitli 
Kars \& Ekberli

Soya Bitkisinin Verim Parametreleri ile Bazı Kimyasal Toprak Özellikleri Arasındaki Pedotransfer Modellerin Uygulanabilirliği bitkiler için farklı modellerin yapılabilmesi için, toprak özelliklerine ve bitkilerin verim unsurlarına ait veri bankasının oluşturulması gereklidir. Modelin uygulanabilirliğinin belirlenmesinde toprak ve iklim koşullarının benzer olduğu çalışma alanlarının toprak ve bitki verilerinden kullanılması gerekmektedir. Kültivasyon işlemlerinin düzenli yapılmaması, iklim koşullarının değişimi, toprak özelliklerinin ve ürün miktarının optimum düzeyde olmaması gibi faktörler, hesaplanan ve ölçülen verim değerleri arasındaki farklılıkların ortaya çıkmasına, dolayısıyla da pratikte uygulanabilir modellerin yapılmamasına neden olabilmektedir. Modellerin kalibrasyonu için, modellerin yapıldığı bölgedeki diğer verim parametrelerin ölçüm değerlerinin kullanılması gerekmektedir. Pedotransfer modellerin geliştirilmesi toprak bilgi sistemlerinin ayrılmaz bir parçası olacaktır. 


\section{Kaynakça}

Alexandrov, V.A., Hoogenboom, G. (2000). The impact of climate variability and change on crop yield in Bulgaria. Agricultural and Forest Meteorology, 104(4): 315-327.

Anonim, 1984. Samsun İli Arazi Varlığı. T.C. Tarım Orman ve Köy İşleri Bakanlığı, Toprak Su Genel Müdürlüğü Yayınları, Ankara. İl rapor No: 55; Genel yayın No: 748

Anonim. (2013). Tohumluk Tescil ve Sertifikasyon Merkez Müdürlüğü. (https://www.tarimorman.gov.tr/BUGEM/TTSM/Belgeler/Tescil/Teknik\%20Talimatlar/End\%C3\%BCstri\%20Bitkileri/soya.pdf) (Erişim tarihi: 25.01.2019)

Anonim. (2016). Türkiye İstatistik Kurumu Temel İstatistikler. http://www.tuik.gov.tr (Erişim Tarihi: 17.04.2017).

Anonymous. (1954). U.S. Salinity Laboratory Staff. Diagnosis and Improvement of Saline and Alkaline Soils. (Ed L.A. Richards). USDA Agriculture Handbook No: 60, U.S. Goverment Printing Office, Washington.

Arıoğlu, H. (2000). Yağ Bitkileri Yetiştirme Ve Islahı. Ders Kitapları Yayın No:A-70C. Çukurova Üniversitesi Ziraat Fakültesi Genel Yayın No:220, Adana.

Arslanoglu, F., Aytac, S., Karaca E. (2005). The Determination of yield criteria of some soybean (Glycine max L.) varieties sowed in Samsun and Sinop locations for second crop production. The Sixth Field Crops Congress of Turkey. In: M. Karaca and M. Bilgen (Editors), Proceeding, vol I: 387-392.

Ay, B. (2012). Türkiye'de ıslah edilmiş yeni soya (Glycine Max. L. Merrill) çeşitlerinin Orta Karadeniz Bölgesi koşullarında verim ve kalite performanslarının belirlenmesi. Yüksek Lisans Tezi, Ondokuz Mayı Üniversitesi Fen Bilimleri Enstitüsü Tarla Bitkileri Anabilim Dalı, 51, Samsun.

Bayraklı, F. (1987). Toprak ve Bitki Analizleri. Ondokuz Mayıs Üniversitesi Yayınları, No:17, Samsun.

Bayraklı, F., Ekberli, İ.A., Cülser, C. (1999). Azerbaycan mil ovası topraklarının verimlilik düzeylerinin deneysel ve matematiksel olarak değerlendirilmesi. Ondokuz Mayıs Üniversitesi Ziraat Fakültesi Dergisi, 14(2): 138-153.

Bhatia, V.S., Singh, P., Wani, S.P., Chauhan, G.S., Kesova, A.V.R., Mishra, A.K., Srinivas, K. (2008). Analysis of potential yields and yield gabs of rainfed soybean in İndia using GROPGRO-Soybean Model. Agricultural And Forest Meteorology, 148: $1252-1265$.

Budka, A., Lacka, A., Gaj, R., Jajor, E., Korbas, K. (2015). Predicting winter wheat yields by comparing regression equations. Crop Protection, 78: 84-91.

Chien, S.H., and R.G. Menon. (1995). Factors affecting the agronomic effectiveness of phosphate rock for direct application. Fertilizer Research, 41:227-34.

Cueff, S., Coquet, Y., Aubertot, J-N., Bel, L., Pot, V., Alletto, L., (2021). Estimation of soil water retention in conservation agriculture using published and new pedotransfer functions. Soil \& Tillage Research, 209: 104967.

Çetin, H. (2010). Soyada fosforlu gübrelemenin verim ve kalite unsurlarına etkilerinin belirlenmesi ve Konya yöresinde soya için uygun fosfor dozunun tespit edilmesi. Yüksek Lisans Tezi, Selçuk Üniversitesi Fen Bilimleri Enstitüsü Tarla Bitkileri Anabilim Dalı. Konya.

Dorsey, J.W., Hardy, L.C. (2018). Sustainability factors in dynamical systems modeling: Simulating the non-linear aspects of multiple equilibria. Ecological Modelling, 368: 69-77.

Ekberli İ, Dengiz O (2016). Bazı Inceptisol ve Entisol alt grup topraklarının fizikokimyasal özellikleriyle 1sısal yayınım katsayısı arasındaki regresyon ilişkilerin belirlenmesi. Toprak Su Dergisi, 5 (2): 1-10.

Ekberli, İ., Dendiz, O. (2017). Bazalt ana materyali ve farklı topografik pozisyon üzerinde oluşmuş toprakların bazı topografik özellikler ve fiziksel-kimyasal özellikleri arasındaki doğrusal regresyon modellerinin belirlenmesi. Toprak Su Dergisi, 6(1): 15-27.

Ersoy, T., Arığlu, H.H. (1988). Ön Üretim İzni Almış Bazı Soya (Glycinemax. L.Merr.) Çeşitlerinin Çukurova Bölgesinde II. Ürün Olarak Yetiştirilebilme Olanakları Üzerinde Bir Araştırma. Çukurova Üniversitesi Fen Bilimleri Enstitüsü. Fen ve Mühendislik Bilimleri Dergisi, 2(1):59-71.

Fageria, N.K., Baligar, V.C., Moreira, A., Moraes. L.A.C. (2013a). Soil phosphorous influence on growth and nutrition of tropical legume cover crops in acidic soil. Communications in Soil Science and Plant Analysis, 44:3340-64.

Fageria, N.K., Moreira, A., Castro, C., Moraes, M.F. (2013b). Optimal Acidity Indices for Soybean Production in Brazilian Oxisols. Communications in Soil Science and Plant Analysis, 44:20, 2941-2951.

Ghorbani, H., Kashi, H., Moghadas, N.H., Emamgholizadeh, S. (2015). Estimation of soil cation exchange capacity using multiple regression, artificial neural networks, and adaptive neuro-fuzzy inference system models in Golestan province, Iran. Communications in Soil Science and Plant Analysis, 46(6): 763-780.

Gülser, C., Candemir, F. (2014). Using soil moisture constants and physical properties to predict saturated hydraulic conductivity. Eurasian Journal of Soil Science, 3(1): 77-81.

Homer, A.D., Özçelik, H., Üstün, A. (2000). Karadeniz bölgesi soya ıslahı çalışmaları. Karadeniz Tarımsal Araştırma Enstitüsü Samsun, 1999 Y1lı Teklif, Gelişme ve Sonuç Raporları, S: 22-30, Samsun. 

Huang, F., Zhan, W., Ju, W., Wang, Z. (2014). Improved reconstruction of soil thermal field using two-depth measurements of soil temperature. Journal of Hydrology, 519: 711-719.

Jackson, M.L. (1962). Soil Chemical Analysis. Prentice Hall. Inc. Englewood Cliffs, New Jersey, USA, pp. $219-221$.

Kacar, B. (1994). Bitki ve Toprağın Kimyasal Analizleri III, Toprak Analizleri. Ankara Üniversitesi Ziraat Fakültesi, Eğitim Araştırma ve Geliştirme Vakfı Yayınları, No: 3, Ankara.

Karagül, E.T., Ay, N., Meriç, Ş., Huz, E. (2011). Ege Bölgesi’nde ana ürün olarak yetiştirilen bazı soya genotiplerinin verimi, verim öğeleri ve nitelikleri üzerinde bir araştırma. Journal of Anadolu, 21(2): 59-66.

Krause, P., Boyle, D.P., Base, F. (2005). Comparison of different efficiency criteria for hydrological model assessment. Advances in Geosciences, 5: 89-97.

Kars, N., Ekberli, İ. (2019). Çarşamba ovasının buğday bitkisi altındaki topraklarının bazı fiziksel ve kimyasal özelliklerinin incelenmesi. Toprak Su Dergisi, 8(1): 18-28.

Kars, N., Ekberli, İ., (2020). The relation between yield indices of maize plant and soil physicochemical characteristics. Eurasian Journal of Soil Science, 9(1): 52-59.

Kosheleva, N.E., Kasimov, N.S., Samonova, O.A. (2002). Regression models fort he behavior of heavy metals in soils of the SmolenskMoskow Upland. Pocvovedeniye, 8: 954-966.

Kumar, A., Pandey, V., Shekh, A.M., Dixit, S.K., Kumar, M. (2008). Evaluation of cropgro-soybean (glycine max. 1. merrill) model under varying environment condition. American-Eurasian Journal of Agronomy, 1(2): 34-40.

Kumar, P., Sarangi, A., Singh, D.K., Parihar, S.S., Sahoo, R.N. (2015). Simulation of salt dynamics in the root zone and yield of wheat cropunder irrigated saline regimes using SWAP model. Agricultural Water Management, 148: 72-83.

Lindsay, L., Norvell, W.A. (1978). Development of a DTPA soil test for zinc, iron, manganese and copper. Soil Science Society of America Journal, 42(3): 421-428.

McBride, R.A. and Joosse, P.J. (1996). Overconsolidation in Agricultural Soils: II. Pedotransfer Functions for Estimating Preconsolidation Stress, Soil Science Society of America Journal, 60: 373-380.

Minasny, B., McBratney, A.B. (2008). Regression rules as a tool for predicting soil properties from infrared reflectance spectroscopy. Chemometrics and Intelligent Laboratory Systems, 94: 72-79.

Moreira, A., Moraes, L.A.C, Moretti, L.G. (2017). Yield, yield components, soil chemical properties, plant physiology, and phosphorus use efficiency in soybean genotypes, Communications in Soil Science and Plant Analysis, 48(20): 2464-2476. DOI: $10.1080 / 00103624.2017 .1416126$.

Murthy, V.R.K. (2002). Crop growth modeling and its applications in agricultural meteorology. Satellite Remote Sensing and GIS Applications in Agricultural Meteorology, 235-261.

Olsen, S.R., Cole, V., Watanabe, F.S., Dean, L.A. (1954). Estimation of Available Phosphorous in Soils by Extraction with Sodium Bicarbonate. USDA Circular, 9398: 1-19.

Ovando, G., Sayago, S., Bocco, M. (2018). Evaluating accuracy of DSSAT model for soybean yield estimation using satellite weather data. ISPRS Journal of Photogrammetry and Remote Sensing, 138: 208-217.

Öztürk, İ., Korkut, K.Z., (2018). Ekmeklik buğday (Triticum aestivum L)'ın farklı gelişme dönemlerinde kuraklığın verim ve verim unsurlarına etkisi. Tekirdă̆ Ziraat Fakültesi Dergisi, 15(2): 128-137.

Rajput, M.A., Sarwar, G., Tahir. K.H. (1987). Variability for some quantitative traits in soybean. Soybean Genetics Newsletter, 14: 113-116.

Richards, L.A. (1954). Diagnosis and Improvement of Saline and Alkali Soils. United States Department of Agriculture, Handbook No: 60, pp. 105-106.

Sağlam, M.T. (1997). Toprak ve Suyun Kimyasal Analiz Yöntemleri. Tekirdağ Üniversitesi Ziraat Fakültesi Yayınları, No: 189.

Schaap, M.G., Leij, F.J., van Genuchten, M.T. (2001). ROSETTA: A computer program for estimating soil hydraulic parameters with hierarchical pedotransfer functions. Journal Hydrology, 251: 163-176.

Sentelhas, P.C., Battist, R., Câmara, G.M.S., Farias, J.R.B., Hampf, A.C., Nendel, C. (2015). The soybean yield gap in Brazil magnitude, causes and possible solutions for sustainable production. Journal of Agricultural Science, 153: 1394-1411.

Shein, E.V., Arkhangelskaya, T.A. (2006). Pedotransfer functions: state of the art, problems, and outlooks. Pocvovedeniye, 10: $1205-1217$.

Şaylan, L., (1996). Soya veriminin CRPSM modeli ile belirlenmesi. Kültür Teknik Derneği Toprak Su Dergisi, 5(1): 12-17.

Taban, S., Çıkılı, Y., Kebeci, F., Taban, N., Sezer, S.M. (2004). Taşköprü yöresinde sarımsak tarımı yapılan toprakların verimlilik durumu ve potansiyel beslenme problemlerinin ortaya konulması. Tarım Bilimleri Dergisi, 10(3): 297-304.

Tamari, S., Wösten, J.H. M., Ruiz-Suárez, J.C. (1996). Testing an artifi cial neural network for predicting soil hydraulic conductivity. Soil Science Society of America Journal, 60: 1732-1741. 
Tayyar Ş., Gül, M.K., (2007). Bazı soya fasulyesi (glycine max (1.) merr.) genotiplerinin ana ürün olarak Biga şartlarındaki performansları. Yüzüncü Yıl Üniversitesi, Ziraat Fakültesi, Tarım Bilimleri Dergisi, 17(2): 55-59.

To, J., Kay, B.D., (2005). Variation in penetrometer resistance with soil properties: the contribution of effective stress and implications for pedotransfer functions. Geoderma, 126: 261-276.

Turan, M., Dengiz, O., Turan Demirăg, İ. (2018). Samsun ilinin Newhall modeline göre toprak sıcaklık ve nem rejimlerinin belirlenmesi. Türkiye Tarımsal Araştırmalar Dergisi, 5(2): 131-142.

Unakıtan, G., Aydın, B., (2012). An econometric analysis of soybean production in Turkey. Journal of Tekirdag Agricultural Faculty, 9(1): 614.

Wang, L., Lia, X., Chen, Y., Yang, K., Chen, D., Zhou, J., Liu, W., Qi, J., Huang, J., (2016). Validation of the global land data assimilation system based onmeasurements of soil temperature profiles. Agricultural and Forest Meteorology, 218-219: 288-297.

Willmott, C.J., Matsuura, K. (2005). Advantages of the mean absolute error (MAE) over the root mean square error (RMSE) in assessing average model performance. Climate Research, 30(1): 79-82.

Willmott, C.J., Robeson, S.M., Matsuura, K. (2012). Short Communication. A refined index of model performance. International Journal of Climatology, 32(13): 2088-2094.

Yegül,U., Eminoğlu, M.B., Türker,U., (2019). Buğdayın Verim ve Kalite Parametrelerinin Toprağın Elektriksel İletkenliği ile İlişkisinin Belirlenmesi Tekirdă̆ Ziraat Fakültesi Dergisi, 16(3): 270-283.

Yetkin, S.G., Arığulu, H. (2009). Çukurova bölgesinde ana ürün koşullarında bazı soya çeşit ve hatlarının verim ve tarımsal özelliklerinin belirlenmesi. Çukurova Üniversitesi Fen Bilimleri Enstitüsü, 20-1: 29-37. 